\title{
Clinical value of serum human epididymis protein 4 assay in the diagnosis of ovarian cancer: a meta-analysis
}

This article was published in the following Dove Press journal:

OncoTargets and Therapy

22 July 2013

Number of times this article has been viewed

\section{Zhijun Yang* \\ Chunyin Wei* \\ Zhaoqing Luo \\ Li Li}

Department of Gynecologic Oncology, Guangxi Medical University, Nanning,

People's Republic of China

*These authors contributed equally to this work
Correspondence: Li Li

Department of Gynecologic Oncology, Cancer Institute and Hospital, Guangxi Medical University, Nanning, Guangxi 53002I, People's Republic of China Email lili@gxmu.edu.cn
Objective: Human epididymis protein 4 (HE4) has been approved for diagnosing ovarian cancer. The goal of this meta-analysis was to evaluate the clinical value of the serum HE4 in the diagnosis of ovarian cancer.

Methods: The PubMed and Embase databases were searched to identify suitable studies. The sensitivity (SEN), specificity (SPE), and positive and negative likelihood ratios (PLR and NLR, respectively) of HE4 for the diagnosis of ovarian cancer were commonly used as bivariates. Summary receiver operating characteristic curves were used to summarize overall test performances. Meta-Disc 1.4 software was used to analyze the data.

Results: A total of 6,269 patients from 31 trials were subjected to meta-analysis. The summary estimates of HE4 for ovarian cancer diagnosis were as follows: SEN 0.73 (95\% confidence interval [CI] 0.71-0.75); SPE 0.89 (95\% CI 0.88-0.90); PLR 7.30 (95\% CI 5.42-9.84); and NLR 0.15 (95\% CI 0.10-0.23). SEN 0.74 (95\% CI 0.72-0.76); SPE 0.89 (95\% CI 0.88-0.90); PLR 7.35 (95\% CI 5.55-9.73); NLR 0.14 (95\% CI 0.09-0.21).

Conclusion: Our study demonstrates that the sensitivity and specificity of HE4 was higher than that of cancer antigen 125. The results indicated that HE4 could be a useful tumor marker for ovarian cancer diagnosis. However, the results of this meta-analysis should be interpreted with caution, due to the heterogeneity among study designs. Further study should pay more attention to the possibility that HE4 can be a marker for monitoring recurrence of ovarian cancer.

Keywords: ovarian cancer, HE4, CA125, meta-analysis

\section{Background}

Ovarian malignant tumor ranks third in female reproductive tract tumors. Only $25 \%$ of patients can be identified at stage I. Compared with stage I, 5-year survival of ovarian cancer patients of stage III and IV has decreased from $95 \%$ to $20 \%-25 \%$. ${ }^{1-3}$ With this high mortality, early diagnosis of ovarian malignant tumor is of great importance. Serum tumor markers are widely used in screening, diagnosis, recurrence detection, and efficacy judgment. Serum cancer antigen (CA)-125 can elevate in 85\% of ovarian cancer patients, with clinical value in preoperative diagnosis and progress monitoring of ovarian cancer. Nevertheless, CA125 levels do not elevate in the early stage of some ovarian cancer patients. It is difficult to establish an early diagnosis of ovarian cancer based on CA125 levels, and they can elevate in some benign gynecological diseases, such as endometriosis, benign ovarian tumors, pelvic inflammatory disease, the menstrual phase, early pregnancy, and laparotomy. Therefore, it is a hot issue for study to search and separate new markers for early diagnosis and disease surveillance of ovarian cancer. 
Human epidermis protein 4 (HE4) is an ovarian cancer marker suggested recently. A study revealed that HE4 is highly expressed in ovarian cancer tissues, whereas it is expressed comparatively lower in precancerous, benign, and normal tissues. Detection of HE4 might have a certain value for diagnosis and monitoring of ovarian cancer. Now, HE4 is studied mostly by individual research centers; the role of the HE4 assay for diagnosing ovarian cancer has not been well-established. Application of evidence-based medicine provides a reliable research method that can integrate the results from different research centers and provide reliable scientific conclusions to guide clinical practice. Therefore, we conducted a meta-analysis based on relevant and available trials to assess the value of serum HE4 for the diagnosis of ovarian cancer to guide clinical treatment.

\section{Materials and methods}

\section{Literature search and inclusion criteria}

Literature searches of the PubMed and Embase databases (January 2000 to May 2013) were performed. Index words included HE4, WFDC2, human epididymis protein 4, human epididymis-specific protein 4 , OC, ovarian cancer, ovarian carcinoma, and ovarian neoplasm.

English-language restriction was imposed. In addition, the reference lists of identified studies were manually checked to include other potentially eligible trials. This process was performed iteratively until no additional articles could be identified.

\section{Inclusion criteria}

All papers with pathological diagnosis of ovarian cancer and serum HE4 value were included. All papers were published from January 2000 to May 2013. There was a clear threshold reference value.

\section{Exclusion criteria}

Papers published before January 2000 or after May 2013 were excluded, as were case reports and reviews and papers without a serum HE4 test value of ovarian cancer, or where there was no clear threshold reference value.

\section{Quality assessment}

The methodological quality of each trial was evaluated by the quality-assessment tool for diagnostic accuracy studies (QUADAS). We requested the relevant information from authors if data were unreported.

The quality and bias of independent research was assessed based on the following aspects: whether the experimental design was scientific, whether inclusion criteria and basic structural characteristics of research objects were clear, whether factors and methods of treatment were accurate, whether statistical methods were appropriate, and whether biases in the study were discussed. Research that met one of these conditions scored 1 point. Quality was reliable when the total score was $\geq 3$ points.

\section{Statistical analyses}

This meta-analysis was performed using Meta-Disc 1.4 software provided by the Cochrane Collaboration (Oxford, UK). Analysis of heterogeneity between studies was done using the $\chi^{2}$ test. When there was no significant heterogeneity between studies $\left(P>0.1, I^{2} \leq 50 \%\right)$, we used fixed-effect meta-analysis and analyzed bias to obtain sensitivity, specificity, positive predictive, and negative predictive values. If there was statistical heterogeneity between studies, the meta-analysis was performed using the random-effects model $\left(P \leq 0.1, I^{2}>50 \%\right)$.

Table I Basic information about included papers

\begin{tabular}{|c|c|c|c|c|}
\hline Study & TP & $\mathbf{F P}$ & $\mathbf{F N}$ & TN \\
\hline Hellström et al ${ }^{4}$ & 20 & I & 17 & 18 \\
\hline Moore et $\mathrm{al}^{5}$ & 49 & 20 & 18 & 146 \\
\hline Havrilesky et $a^{6}$ & 172 & 54 & 28 & 342 \\
\hline Dong et $\mathrm{al}^{7}$ & 19 & 0 & 11 & 182 \\
\hline Montagnana et $\mathrm{a}^{8}$ & 42 & 13 & 0 & 98 \\
\hline Huhtinen et $\mathrm{al}^{9}$ & 10 & 3 & 4 & 66 \\
\hline Abdel-Azeez et al ${ }^{10}$ & 34 & 3 & 7 & 46 \\
\hline Andersen et al ${ }^{\prime \prime}$ & 31 & 0 & I & 158 \\
\hline Chen et $\mathrm{al}^{12}$ & 12 & 6 & 0 & 31 \\
\hline Ke and $\mathrm{Liu}^{13}$ & 29 & 11 & 0 & 92 \\
\hline Liu et $\mathrm{a}^{14}$ & 53 & 39 & 0 & 95 \\
\hline Ma et al ${ }^{15}$ & 56 & 38 & 0 & 95 \\
\hline Wang et $\mathrm{al}^{16}$ & 26 & 2 & 4 & 100 \\
\hline Xu et al ${ }^{17}$ & 19 & 6 & 0 & 31 \\
\hline Yao et $\mathrm{al}^{18}$ & 21 & 9 & 0 & 61 \\
\hline Lu et al $^{19}$ & 45 & 33 & 0 & 25 \\
\hline Liu et $\mathrm{a}^{20}$ & 29 & 7 & 0 & 46 \\
\hline Montagnana et $\mathrm{al}^{21}$ & 42 & 6 & 13 & 92 \\
\hline Van Gorp et $\mathrm{a}^{23}$ & 119 & 34 & 42 & 194 \\
\hline Moore et $\mathrm{al}^{24}$ & 83 & 6 & 36 & 287 \\
\hline Kim et $\mathrm{al}^{25}$ & 57 & 4 & 21 & 77 \\
\hline Jacob et $\mathrm{al}^{26}$ & 25 & 10 & 4 & 61 \\
\hline Holcomb et $\mathrm{a}^{27}$ & 16 & 16 & 2 & 179 \\
\hline Escudero et $\mathrm{a}^{28}$ & 95 & 32 & 0 & 101 \\
\hline Chang et $\mathrm{al}^{29}$ & 38 & 2 & 14 & 64 \\
\hline Bandiera et $\mathrm{al}^{30}$ & 90 & 23 & 3 & 137 \\
\hline Zheng and $\mathrm{Gao}^{31}$ & 103 & 28 & 0 & 126 \\
\hline Karlsen et al ${ }^{32}$ & 230 & 22 & 298 & 511 \\
\hline Kadija et $\mathrm{al}^{33}$ & 19 & 10 & 63 & 20 \\
\hline Hamed et $\mathrm{al}^{34}$ & 27 & 3 & I & 29 \\
\hline Azzam et $\mathrm{al}^{35}$ & 49 & II & 3 & 57 \\
\hline
\end{tabular}

Abbreviations: TP, true positive; FP, false positive; FN, false negative; TN, true negative. 
Table 2 Quality-assessment tool for diagnostic accuracy studies (QUADAS) measure for included papers

\begin{tabular}{|c|c|c|c|c|c|c|}
\hline \multirow[t]{2}{*}{ Study } & \multicolumn{3}{|c|}{ Risk of bias } & \multicolumn{3}{|c|}{ Applicability concerns } \\
\hline & $\begin{array}{l}\text { Patient } \\
\text { selection }\end{array}$ & Index test & $\begin{array}{l}\text { Reference } \\
\text { standard }\end{array}$ & $\begin{array}{l}\text { Patient } \\
\text { selection }\end{array}$ & Index test & $\begin{array}{l}\text { Reference } \\
\text { standard }\end{array}$ \\
\hline Hellström et al ${ }^{4}$ & $\uparrow$ & $?$ & $?$ & $\uparrow$ & $\uparrow$ & $\uparrow$ \\
\hline Moore et $\mathrm{al}^{5}$ & $?$ & $\uparrow \uparrow$ & $\uparrow$ & $\uparrow$ & $\uparrow$ & $\uparrow$ \\
\hline Havrilesky et $\mathrm{al}^{6}$ & $\uparrow$ & $\uparrow$ & $\uparrow$ & $\uparrow$ & $\uparrow \uparrow$ & $\uparrow$ \\
\hline Dong et $\mathrm{al}^{7}$ & $?$ & $\uparrow$ & $\uparrow$ & $\uparrow$ & $\uparrow$ & $\uparrow$ \\
\hline Montagnana et al ${ }^{8}$ & $\uparrow$ & $\uparrow \uparrow$ & $\uparrow$ & $?$ & $\uparrow$ & $\uparrow$ \\
\hline Huhtinen et $\mathrm{al}^{9}$ & $?$ & $?$ & $\uparrow$ & $?$ & $?$ & $\uparrow$ \\
\hline Abdel-Azeez et al $^{10}$ & $?$ & $?$ & $?$ & $\uparrow$ & $\uparrow$ & $\uparrow$ \\
\hline Andersen et $\mathrm{al}^{\prime \prime}$ & $?$ & $\uparrow$ & $\uparrow$ & $?$ & $\uparrow$ & $\uparrow$ \\
\hline Chen et $\mathrm{al}^{12}$ & $\uparrow$ & $\uparrow \uparrow$ & $\uparrow$ & $\uparrow$ & $\uparrow$ & $\uparrow$ \\
\hline Ke and $\mathrm{Liu}^{13}$ & $\uparrow$ & $\uparrow$ & $\uparrow$ & $?$ & $\uparrow$ & $\uparrow$ \\
\hline Liu et $\mathrm{al}^{14}$ & $?$ & $\uparrow$ & $\uparrow$ & $\uparrow$ & $\uparrow$ & $\uparrow$ \\
\hline Ma et $\mathrm{al}^{15}$ & $\uparrow$ & $\uparrow$ & $\uparrow$ & $\uparrow$ & $\uparrow$ & $\uparrow$ \\
\hline Wang et al ${ }^{16}$ & $\uparrow$ & $\uparrow \uparrow$ & $\uparrow$ & $\uparrow$ & $\uparrow$ & $\uparrow$ \\
\hline Xu et al ${ }^{17}$ & $\uparrow$ & $\uparrow$ & $\uparrow$ & $\uparrow$ & $\uparrow$ & $\uparrow$ \\
\hline Yao et $\mathrm{al}^{18}$ & $\uparrow$ & $\uparrow$ & $\uparrow$ & $\uparrow$ & $\uparrow$ & $\uparrow$ \\
\hline Lu et al ${ }^{19}$ & $\uparrow$ & $\uparrow$ & $\uparrow$ & $\uparrow$ & $\uparrow \uparrow$ & $\uparrow$ \\
\hline Liu et $\mathrm{a}^{20}$ & $\uparrow$ & $\uparrow \uparrow$ & $\uparrow$ & $\uparrow$ & $\uparrow$ & $\uparrow$ \\
\hline Montagnana et $\mathrm{a}^{21}$ & $?$ & $\uparrow$ & $\uparrow$ & $?$ & $\uparrow$ & $\uparrow$ \\
\hline Van Gorp et $\mathrm{a}^{23}$ & $\uparrow$ & $\uparrow$ & $\uparrow$ & $\uparrow$ & $\uparrow \uparrow$ & $\uparrow$ \\
\hline Moore et $\mathrm{al}^{24}$ & $\uparrow$ & $\uparrow$ & $\uparrow$ & $\uparrow$ & $\uparrow$ & $\uparrow$ \\
\hline Kim et $\mathrm{al}^{25}$ & $\uparrow$ & $\uparrow$ & $\uparrow$ & $\uparrow$ & $\uparrow \uparrow$ & $\uparrow$ \\
\hline Jacob et $\mathrm{al}^{26}$ & $?$ & $\uparrow$ & $\uparrow$ & $?$ & $\uparrow \uparrow$ & $\uparrow$ \\
\hline Holcomb et $\mathrm{al}^{27}$ & $\uparrow \uparrow$ & $\uparrow$ & $\uparrow$ & $?$ & $\uparrow \uparrow$ & $\uparrow$ \\
\hline Escudero et $\mathrm{al}^{28}$ & $\uparrow$ & $\uparrow$ & $\uparrow$ & $\uparrow$ & $\uparrow$ & $\uparrow$ \\
\hline Chang et $\mathrm{al}^{29}$ & $?$ & $\uparrow$ & $\uparrow$ & $\uparrow$ & $\uparrow$ & $\uparrow$ \\
\hline Bandiera et $\mathrm{a}^{30}$ & $\uparrow$ & $?$ & $?$ & $\uparrow$ & $\uparrow$ & $\uparrow$ \\
\hline Zheng and $\mathrm{Gao}^{3 !}$ & $\uparrow$ & $\uparrow$ & $\uparrow$ & $\uparrow$ & $\uparrow$ & $\uparrow$ \\
\hline Karlsen et $\mathrm{al}^{32}$ & $\uparrow$ & $\uparrow \uparrow$ & $\uparrow$ & $\uparrow$ & $\uparrow$ & $\uparrow$ \\
\hline Kadija et $\mathrm{al}^{33}$ & $\uparrow$ & $?$ & $?$ & $\uparrow$ & $\uparrow$ & $\uparrow$ \\
\hline Hamed et al ${ }^{34}$ & $\uparrow$ & $?$ & $\uparrow$ & $?$ & $\uparrow$ & $\uparrow$ \\
\hline Azzam et $\mathrm{al}^{35}$ & $\uparrow$ & $?$ & $?$ & $\uparrow$ & $\uparrow$ & $\uparrow$ \\
\hline
\end{tabular}

Notes: $\uparrow$, Low risk; $\uparrow \uparrow$, high risk; ?, unclear risk.

\begin{tabular}{|l|l|}
\hline Review $(\mathrm{n}=38)$ \\
-No available data of incidence $(\mathrm{n}=68)$
\end{tabular}

Figure I Selection process for articles included in the meta-analysis. 


\section{Results}

\section{Basic information and quality evaluation of document retrieval}

Basic information on studies included is shown in Table 1. A total of 291 potentially relevant papers were identified based on the search terms. Finally, 31 papers were scrutinized in full text as appropriate. The selection process for articles included in the meta-analysis is shown in Figure 1. These studies were published between 2010 and 2013. The size of the articles ranged from 49 to 1,061 (total 6,269) words.

\section{Quality evaluation of literature}

The quality and bias of 31 papers were evaluated based on the evaluation criteria. Risk of bias and applicability concerns were used to evaluate the quality of the literature. Most studies were regarded as being at high risk of bias, and patient selection was unclear (description of QUADAS is shown in Table 2).

\section{Meta-analysis}

The heterogeneity analysis revealed a less homogeneous $\left(P<0.00001, I^{2}=96.0 \%\right)$. The meta-analysis was

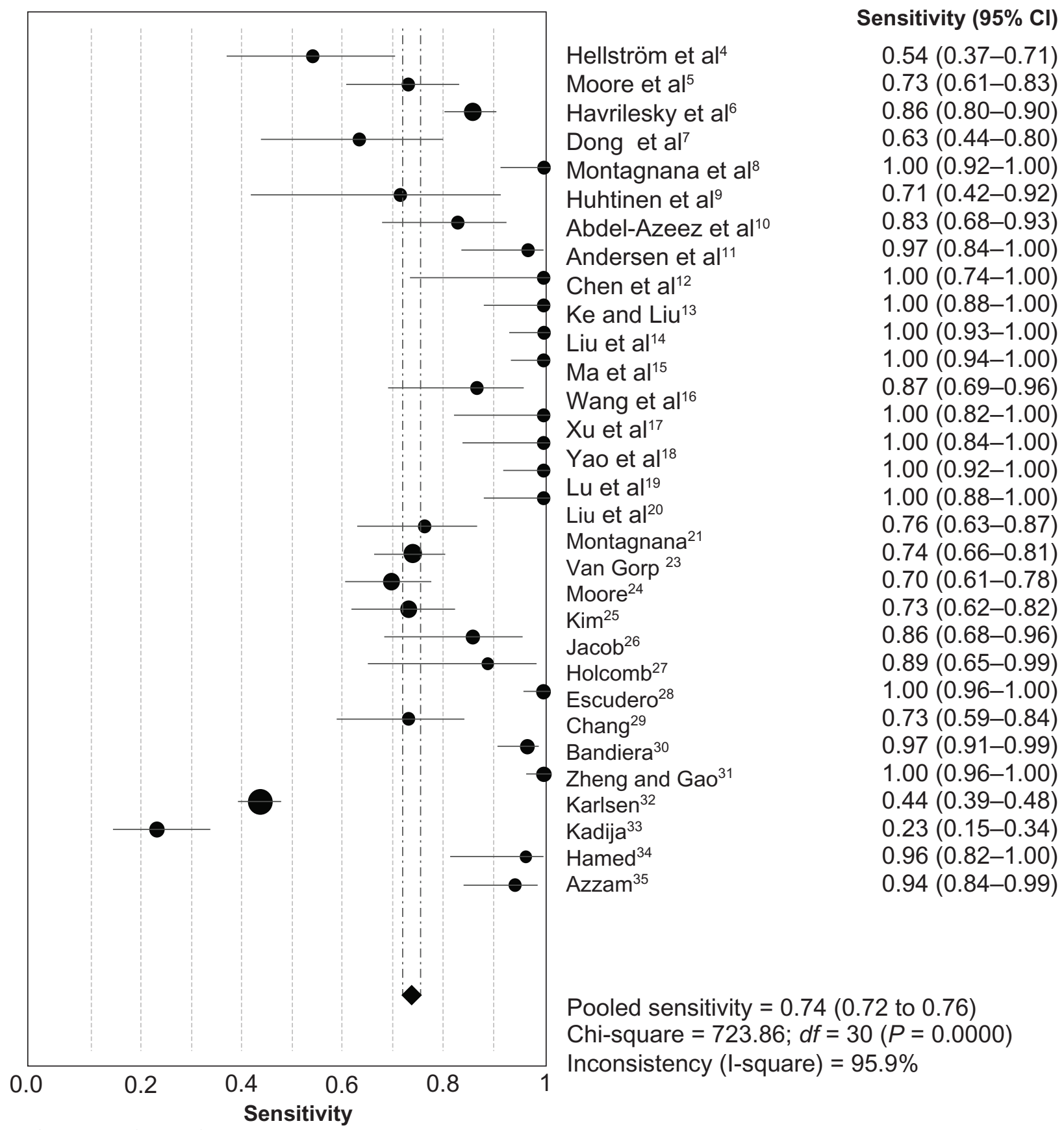

Figure 2 Forest plot of analyses for sensitivity. 
performed using the random-effects model. The results showed sensitivity and specificity of serum HE4 in the diagnosis of ovarian cancer was 0.74 (95\% CI 0.72-0.76), and 0.89 (95\% CI, 0.88-0.90), respectively (Figures 2 and 3 ). The positive and negative predictive values of serum HE4 in the diagnosis of ovarian cancer were $7.28(95 \%$ CI 5.48-9.68), and 0.14 (95\% CI 0.09-0.22), respectively (Figures 4 and 5). The area under the summary receiver operating-characteristic curve was 0.96 (0.95-0.98) (Figure 6). The asymmetry of the funnel plots using Egger's and Begg's tests showed that there was publication bias among the included studies (Egger's test, $P=0.010$; Begg's test, $P=0.009$ ) (Figure 7).

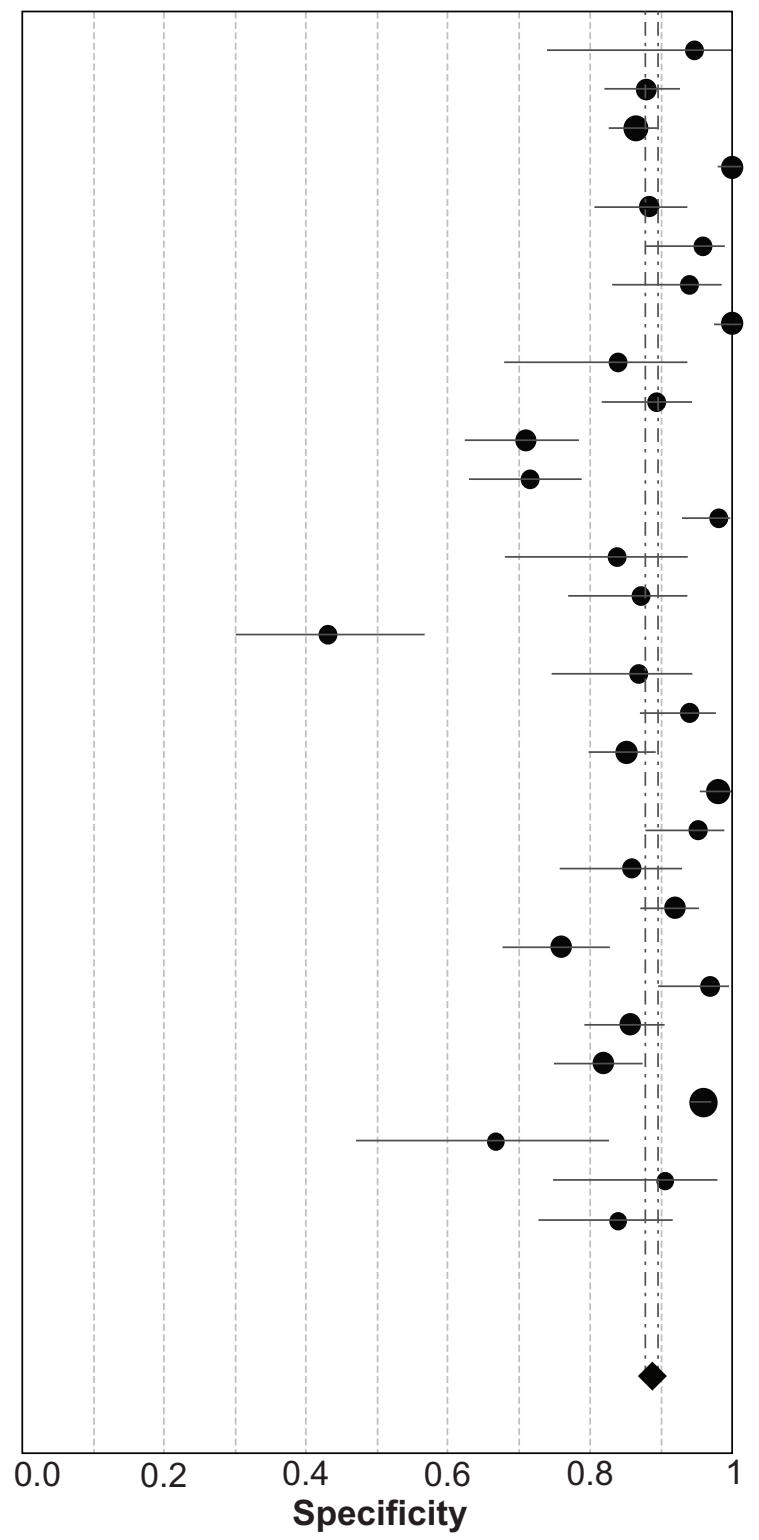

Hellström et al ${ }^{4}$ Moore et al ${ }^{5}$ Havrilesky et $\mathrm{al}^{6}$ Dong et $\mathrm{al}^{7}$ Montagnana et $\mathrm{al}^{8}$ Huhtinen et $\mathrm{al}^{9}$ Abdel-Azeez et al ${ }^{10}$

Andersen et al ${ }^{11}$

Chen et $\mathrm{al}^{12}$

$\mathrm{Ke}$ and $\mathrm{Liu}^{13}$

Liu et al ${ }^{14}$

Ma et al ${ }^{15}$

Wang et al ${ }^{16}$

$\mathrm{Xu}$ et $\mathrm{al}^{17}$

Yao et $\mathrm{al}^{18}$

Lu et $\mathrm{al}^{19}$

Liu et $\mathrm{al}^{20}$

Montagnana et $\mathrm{al}^{21}$

Van Gorp et $\mathrm{al}^{23}$

Moore et $\mathrm{al}^{24}$

Kim et $\mathrm{al}^{25}$

Jacob et al ${ }^{26}$

Holcomb et al ${ }^{27}$

Escudero et al ${ }^{28}$

Chang et al ${ }^{29}$

Bandiera et a ${ }^{30}$

Zheng and $\mathrm{GaO}^{31}$

Karlsen et al ${ }^{32}$

Kadija et al ${ }^{33}$

Hamed et al $^{34}$

Azzam et $\mathrm{al}^{35}$

\section{Specificity $(95 \% \mathrm{CI})$}

$$
\begin{aligned}
& 0.95(0.74-1.00) \\
& 0.88(0.82-0.92) \\
& 0.86(0.83-0.90) \\
& 1.00(0.98-1.00) \\
& 0.88(0.81-0.94) \\
& 0.96(0.88-0.99) \\
& 0.94(0.83-0.99) \\
& 1.00(0.98-1.00) \\
& 0.84(0.68-0.94) \\
& 0.89(0.82-0.95) \\
& 0.71(0.62-0.78) \\
& 0.71(0.63-0.79) \\
& 0.98(0.93-1.00) \\
& 0.84(0.68-0.94) \\
& 0.87(0.77-0.94) \\
& 0.43(0.30-0.57) \\
& 0.87(0.75-0.95) \\
& 0.94(0.87-0.98) \\
& 0.85(0.80-0.89) \\
& 0.98(0.96-0.99) \\
& 0.95(0.88-0.99) \\
& 0.86(0.76-0.93) \\
& 0.92(0.87-0.95) \\
& 0.76(0.68-0.83) \\
& 0.97(0.89-1.00) \\
& 0.86(0.79-0.91) \\
& 0.82(0.75-0.88) \\
& 0.96(0.94-0.97) \\
& 0.67(0.47-0.83) \\
& 0.91(0.75-0.98) \\
& 0.84(0.73-0.92) \\
&
\end{aligned}
$$

Pooled specificity $=0.89(0.88$ to 0.90$)$

Chi-square $=363.10 ; d f=30(P=0.0000)$

Inconsistency (I-square) $=91.7 \%$

Figure 3 Forest plot of analyses for specificity. 


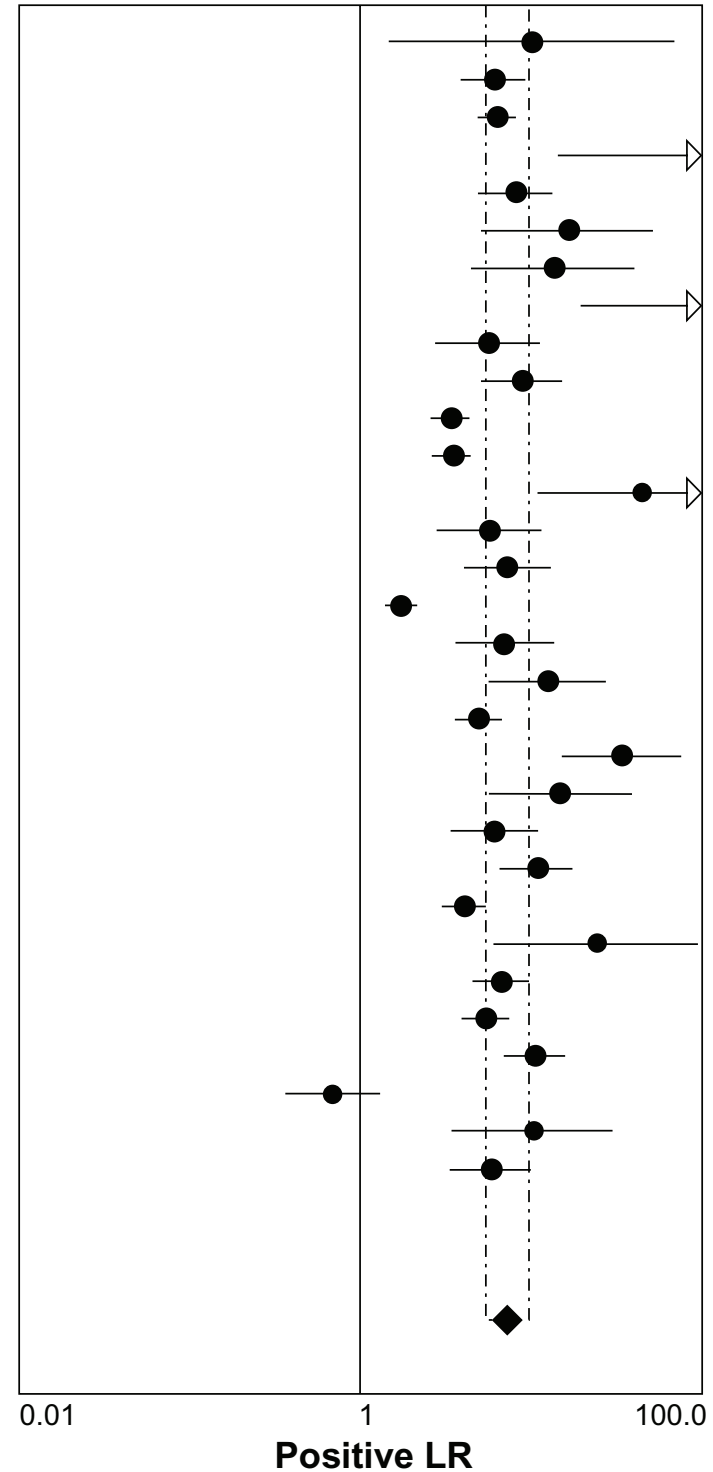

Figure 4 Forest plot of analyses for positive LR.

Abbreviations: $\mathrm{Cl}$, confidence interval; df, degrees of freedom; LR, likelihood ratio.

HE4 is also known as WAP four-disulfide core domain protein 2 , the coding gene of which was separated from the distal epithelium epidermis in 1991. The encoded protein is mainly composed of WAP four-disulfide core. Hellström et al ${ }^{4}$ was the first to subject the HE4 protein to a double-blind test by enzyme-linked immunosorbent assay (ELISA), and found the sensitivity of HE4 in the detection of ovarian cancer was equal to CA125 and the specificity even higher than CA125.

This is a comprehensive systematic review and metaanalysis of 31 articles to evaluate the clinical value of the serum HE4 assay in the diagnosis of ovarian cancer. We
Hellström et $\mathrm{al}^{4}$ Moore et $\mathrm{al}^{5}$ Havrilesky et $\mathrm{al}^{6}$ Dong et $\mathrm{al}^{7}$ Montagnana et $\mathrm{al}^{8}$ Huhtinen et al ${ }^{9}$ Abdel-Azeez et al $^{10}$ Andersen et al ${ }^{11}$ Chen et al ${ }^{12}$ $\mathrm{Ke}$ and $\mathrm{Liu}^{13}$ Liu et al ${ }^{14}$ Ma et $\mathrm{al}^{15}$ Wang et $\mathrm{al}^{16}$ $X u$ et al $^{17}$ Yao et $a^{18}$ Lu et $\mathrm{al}^{19}$ Liu et $a^{20}$ Montagnana et $\mathrm{al}^{21}$ Van Gorp et $\mathrm{al}^{23}$ Moore et $\mathrm{al}^{24}$ Kim et al ${ }^{25}$ Jacob et $\mathrm{al}^{26}$ Holcomb et $\mathrm{al}^{27}$ Escudero et $\mathrm{al}^{28}$ Chang et $\mathrm{al}^{29}$ Bandiera et $\mathrm{al}^{30}$ Zheng and $\mathrm{Gao}^{31}$ Karlsen et $\mathrm{al}^{32}$ Kadija et al ${ }^{33}$ Hamed et $\mathrm{al}^{34}$ Azzam et $\mathrm{al}^{35}$

Random effects model

Pooled positive LR = 7.28 (5.48 to 9.68)

Cochran- $\mathrm{Q}=293.65 ; d f=30(P=0.0000)$

Inconsistency (I-square) $=89.8 \%$

Tau-squared $=0.4964$

\section{Positive LR (95\% Cl)}

$10.27(1.49-70.81)$

6.07 (3.93-9.39)

$6.31(4.89-8.13)$

$230.23(14.27-3,715.46)$

$8.20(4.97-13.54)$

$16.43(5.17-52.16)$

$13.54(4.49-40.90)$

$303.55(19.05-4,836.70)$

$5.62(2.77-11.41)$

$8.89(5.15-15.37)$

$3.39(2.60-4.41)$

$3.45(2.64-4.51)$

44.20 (11.13-175.59)

$5.70(2.82-11.52)$

$7.30(4.03-13.25)$

$1.74(1.39-2.18)$

7.08 (3.64-13.78)

$12.47(5.67-27.46)$

$4.96(3.59-6.85)$

34.06 (15.29-75.860)

$14.80(5.64-38.84)$

$6.12(3.38-11.07)$

$10.83(6.59-17.81)$

$4.10(3.04-5.53)$

$24.12(6.10-95.35)$

$6.73(4.60-9.84)$

$5.41(3.88-7.54)$

$10.55(6.93-16.07)$

$0.70(0.37-1.32)$

$10.29(3.49-30.28)$

$5.83(3.38-10.05)$

reached a contradictory conclusion. Wu et al ${ }^{38}$ and $\mathrm{Yu}$ et a $\mathrm{a}^{36}$ suggested that HE4 was better than CA125. However $\mathrm{Li}$ et $\mathrm{al}^{37}$ showed that HE4 was not better than CA125, for either epithelial ovarian cancer or ovarian cancer prediction. The main finding of our meta-analysis seems to strengthen the conclusions of $\mathrm{Wu}$ et $\mathrm{al}^{38}$ and $\mathrm{Yu}$ et al ${ }^{36}$ However, the results of this meta-analysis should be interpreted with caution, due to the heterogeneity among study designs. In detail, the previous meta-analyses included nine, twelve, and eleven articles, respectively, including twelve studies described here. Meanwhile, articles published in 2012 and 2013 were also included. Two previous meta-analyses ${ }^{36,38}$ and 


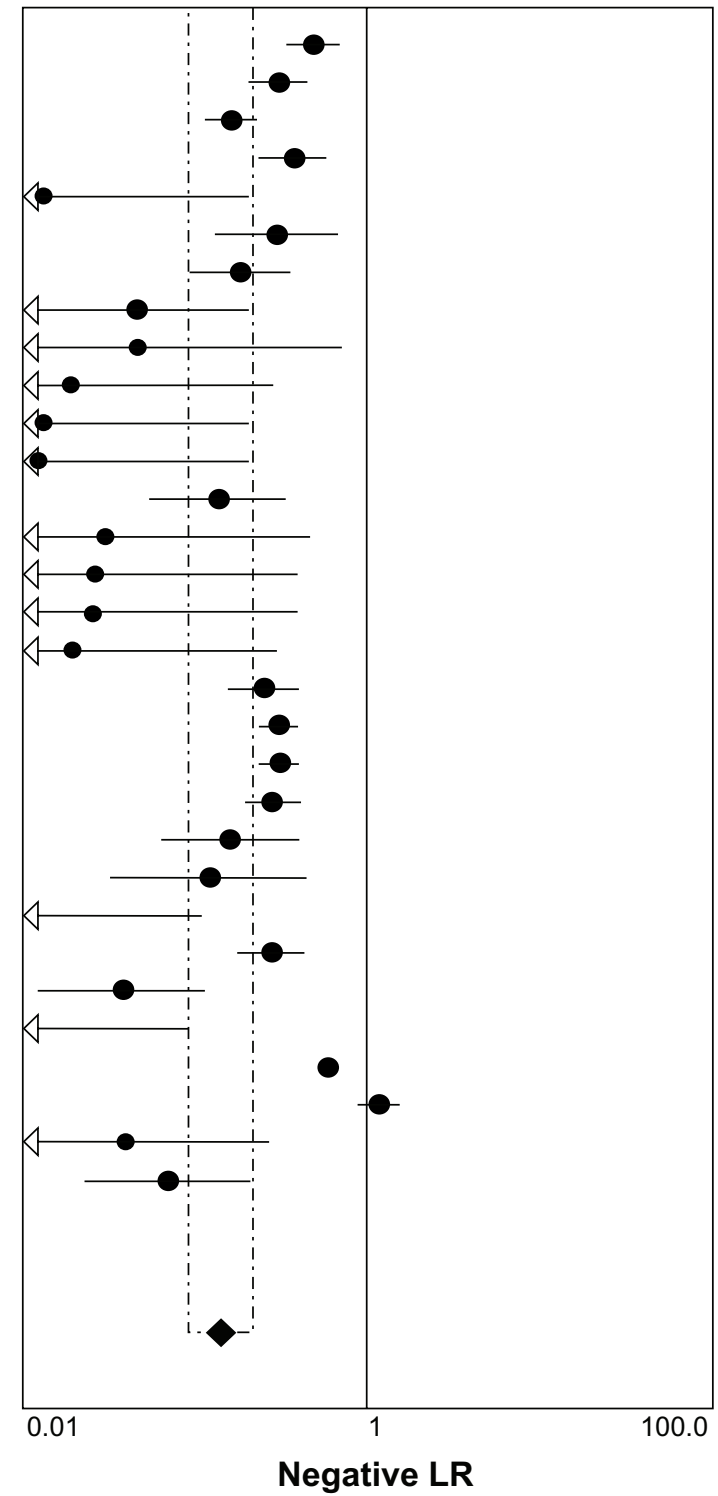

Figure 5 Forest plot of analyses for negative LR.

Abbreviations: $\mathrm{Cl}$, confidence interval; $\mathrm{df}$, degrees of freedom; LR, likelihood ratio.

our meta-analysis showed that the sensitivity and specificity of HE4 was higher than that of CA125. These results are not conclusive, as they are not adequately powered for unified cutoff, control group (healthy women or women with benign disease), and different methods to evaluate HE4 in serum (ELISA, chemiluminescent microparticle immunoassay, bead-based array system).

In 2008, Moore et $\mathrm{al}^{5}$ reported that as a single ovarian tumor marker, the sensitivity of serum HE4 in diagnosis of ovarian cancer was $72.9 \%$ When HE4 combined with CA125, sensitivity and specificity were $76.4 \%$ and $95 \%$, respectively, but when HE4 combined with other tumor markers, the

\section{Negative LR (95\% Cl)}

\begin{tabular}{|c|c|}
\hline Hellström et al ${ }^{4}$ & $0.48(0.34-0.70)$ \\
\hline Moore et $\mathrm{al}^{5}$ & $0.31(0.20-0.46)$ \\
\hline Havrilesky et al ${ }^{6}$ & $0.16(0.11-0.23)$ \\
\hline Dong et $\mathrm{al}^{7}$ & $0.37(0.24-0.59)$ \\
\hline Montagnana et $\mathrm{al}^{8}$ & $0.01(0.00-0.21)$ \\
\hline Huhtinen et $\mathrm{al}^{9}$ & $0.30(0.13-0.68)$ \\
\hline Abdel-Azeez et $a^{10}$ & $0.18(0.09-0.36)$ \\
\hline Andersen et $\mathrm{al}^{11}$ & $0.05(0.01-0.22)$ \\
\hline Chen et $\mathrm{al}^{12}$ & $0.05(0.00-0.71)$ \\
\hline Ke and $\mathrm{Liu}^{13}$ & $0.02(0.00-0.29)$ \\
\hline Liu et $\mathrm{al}^{14}$ & $0.01(0.00-0.21)$ \\
\hline Ma et $\mathrm{al}^{15}$ & $0.01(0.00-0.19)$ \\
\hline Wang et $\mathrm{al}^{16}$ & $0.14(0.05-0.34)$ \\
\hline Xu et al ${ }^{17}$ & $0.03(0.00-0.47)$ \\
\hline Yao et $a^{18}$ & $0.03(0.00-0.41)$ \\
\hline Lu et $\mathrm{al}^{19}$ & $0.03(0.00-0.40)$ \\
\hline Liu et $\mathrm{al}^{20}$ & $0.02(0.00-0.30)$ \\
\hline Montagnana et $\mathrm{a}^{21}$ & $0.25(0.16-0.41)$ \\
\hline Van Gorp et $\mathrm{al}^{23}$ & $0.31(0.24-0.40)$ \\
\hline Moore et $\mathrm{al}^{24}$ & $0.31(0.23-0.41)$ \\
\hline Kim et $\mathrm{al}^{25}$ & $0.28(0.20-0.41)$ \\
\hline Jacob et $\mathrm{al}^{26}$ & $0.16(0.06-0.40)$ \\
\hline Holcomb et $\mathrm{al}^{27}$ & $0.12(0.03-0.45)$ \\
\hline Escudero et $\mathrm{a}^{28}$ & $0.01(0.00-0.11)$ \\
\hline Chang et $\mathrm{al}^{29}$ & $0.28(0.18-0.44)$ \\
\hline Bandiera et $\mathrm{al}^{30}$ & $0.04(0.01-0.11)$ \\
\hline Zheng and $\mathrm{Gao}^{31}$ & $0.01(0.00-0.09)$ \\
\hline Karlsen et al ${ }^{32}$ & $0.59(0.55-0.64)$ \\
\hline Kadija et $\mathrm{al}^{33}$ & $1.15(0.87-1.52)$ \\
\hline Hamed et $\mathrm{al}^{34}$ & $0.04(0.01-0.27)$ \\
\hline Azzam et $a^{35}$ & $0.07(0.02-0.21)$ \\
\hline
\end{tabular}

Random effects model

Pooled Negative LR $=0.14$ (0.09 to 0.22$)$

Cochran-Q $=620.25 ; d f=30(P=0.0000)$

Inconsistency (I-square) $=95.2 \%$

Tau-squared $=1.0137$ increase in sensitivity was very low. HE4 may be the best marker used alone for stage I disease, because the sensitivity of combination with CA125 or other ovarian cancer markers cannot increase. Montagnana et $\mathrm{al}^{8}$ assayed the preoperative serum concentration of both HE4 and CA125 in patients with different forms of benign and malignant pelvic masses. The results showed that the median CA125 and HE4 serum levels were significantly higher among ovarian cancer patients compared with healthy subjects and with those with benign mass. The receiver operating characteristic-curve analysis on healthy controls and patients with ovarian cancers revealed that HE4 had a significantly higher area under the curve when 


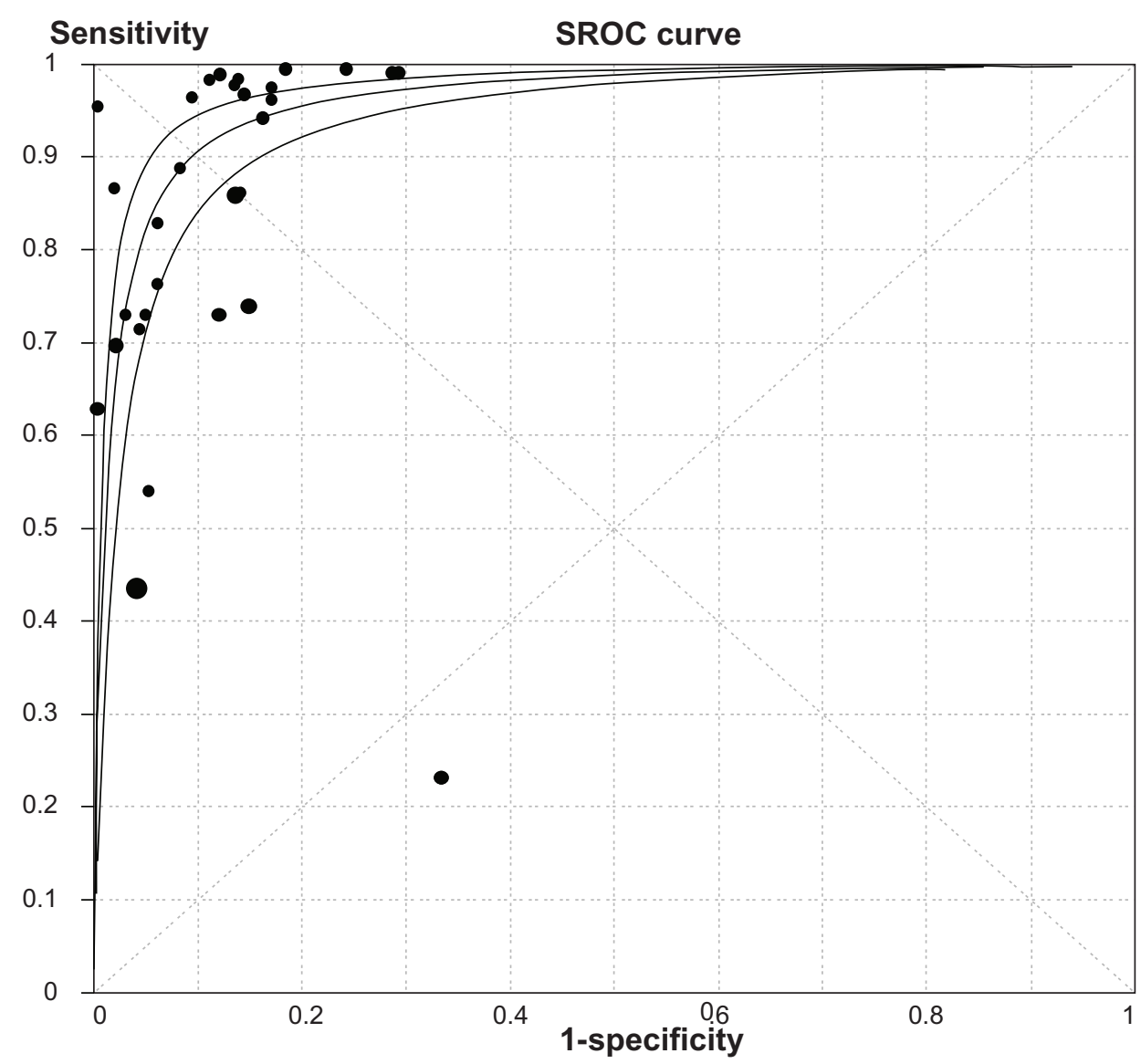

Symmetric SROC

AUC $=0.9588$

$\mathrm{SE}(\mathrm{AUC})=0.0088$

$Q^{*}=0.9027$

SE $\left(Q^{*}\right)=0.0128$

Figure 6 SROC curves from the bivariate model.

Abbreviations: SROC, summary receiver operating characteristic; AUC, area under curve; SE, standard error; $Q^{*}$, index.

Begg's funnel plot with pseudo 95\% confidence limits

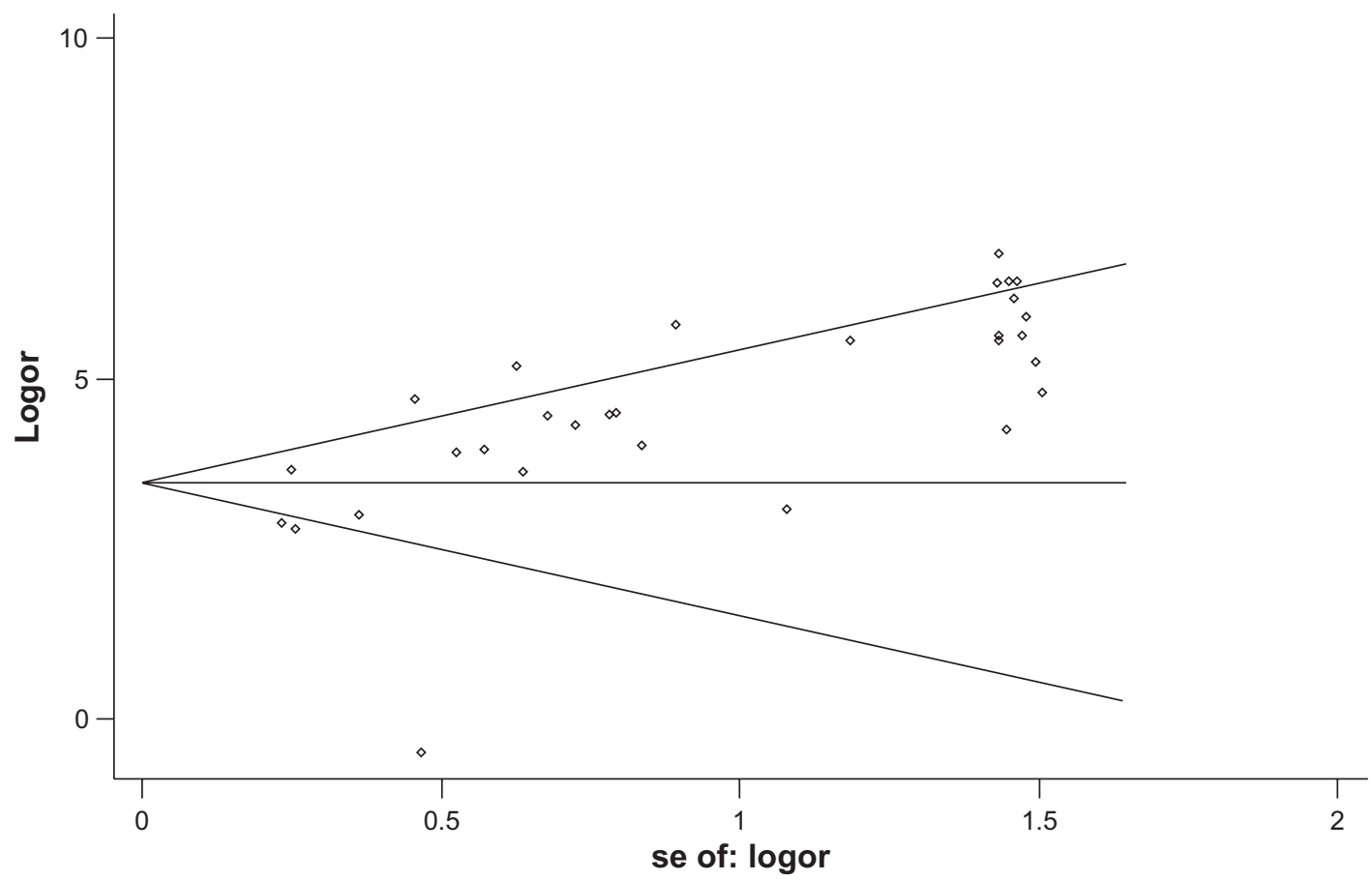

Figure 7 Tests for publication bias.

Abbreviations: se, standard error; logor, log odds ratio. 
compared with CA125 (0.99 vs 0.91), with sensitivity and specificity of $98 \%$ and $100 \%$, respectively. The sensitivity and specificity of HE4 are higher than CA125. Thus, HE4 is considered a promising ovarian cancer marker. In this study, we conducted a meta-analysis to explore further the value of HE4 in the diagnosis of ovarian cancer. The specificity was $95 \%$ (95\% CI $0.88-0.90)$. The positive predictive value was 7.35 (95\% CI, 5.55-9.73). The negative predictive value was 0.14 (95\% CI, 0.09-0.21). The results and reports revealed that the sensitivity of HE4 in detection ovarian cancer is the same as CA125, but specificity is higher than CA125. It suggested that HE4 is a promising marker of ovarian cancer for clinical application. In addition, this study shows the funnel plot is asymmetric. An unfilled corner at the bottom of the graph indicated that there was bias in the research. It is necessary to collect more data to improve the quality of research. In addition, there are still many papers in which HE4 serum was tested but concentration of HE4 in serum was not classified as positive or negative. These only mentioned the median value or range of ovarian cancers, benign diseases, and the control group.

One potential limitation of the present meta-analysis is that the cutoff values of HE4 used among the studies were various. There is no gold standard for the cutoff value and method to evaluate HE4. The heterogeneity with regard to the cutoff value of HE4, assay method, menopausal status, and small samples may also account for the lack of clear evidence to support HE4 as a potential tumor marker for ovarian cancer diagnosis. The second limitation is that we were unable to assess the impact of unpublished papers on publication bias. The third limitation is that the stage of ovarian cancer has insufficient statistical power. Although the evidence of diagnostic effectiveness in detecting early stage tumors is of pivotal relevance, there are currently not enough studies for estimating HE4 performance in this clinical scenario. Additional studies or data are warranted, particularly to evaluate HE4 capability to identify ovarian cancer at an early stage.

Several articles have reported on HE4 in the early diagnosis of ovarian cancer, and found its sensitivity (76.9\%-82.7\%) to be higher than CA125 (45.9\%). ${ }^{4,7} \mathrm{HE} 4$ is also reported in some literature for ovarian cancer disease surveillance. Allard et $\mathrm{al}^{22}$ reported that $83.8 \%$ of patients' CA125 or HE4 levels matched the clinical state. Meanwhile, more and more research has focused on the clinical performance of the risk of ovarian malignancy algorithm (ROMA) and on CA125 and HE4. Sandri et al ${ }^{39}$ demonstrated that the ROMA index combined the advantage of each single marker and reached a sensitivity of $89.3 \%$ and a specificity of $81.7 \%$. However, the results should be interpreted with caution due to heterogeneity. Such heterogeneity means there cannot be a uniform standard in ROMA projects, at least in the beginning. Further indicated that HE4 can be a marker to monitor recurrence of ovarian cancer, which is consistent with the CA125.

\section{Conclusion}

The studies described indicate that HE4 is valuable as an ovarian tumor marker in diagnosis and monitoring the disease state. The value of serum HE4 in diagnosis and disease monitoring of ovarian cancer still needs large-scale and multicenter randomized study.

\section{Acknowledgment}

This work was supported by a grant from the Provincial Research Project Funding of Guangxi, People's Republic of China (2010GXNSFD013053 and 2011Z2011217).

\section{Disclosure}

The authors report no conflicts of interest in this work.

\section{References}

1. Bast RC Jr. Status of tumor markers in ovarian cancer screening. J Clin Oncol. 2003;21:200s-205s.

2. Piver MS, Baker TR, Driscoll DL. Lack of substantial five year diseasefree survival by primary aggressive surgery and cisplatin-based chemotherapy or by salvage intraperitoneal cisplatin-based chemotherapy. Eur J Gynaecol Oncol. 1990;11:243-250.

3. Ozols R, Rubin S, Thomas G, Robboy SJ. Epithelial ovarian cancer. In: Hoskins WJ, Perez CA, Young RC, Barakat R, Markman M, Randall M, editors. Principles and Practice of Gynecologic Oncology. 4th ed. Philadelphia: Lippincott Williams \& Wilkins; 2005:895-989.

4. Hellström I, Rayeraft J, Hayden-Ledbetter M, et al. The HE4 (WFDC2) protein is a biomarker for ovarian carcinoma. Cancer Res. 2003;63:3695-3700.

5. Moore RG, Brown AK, Miller MC, et al. The use of multiple novel tumor biomarkers for the detection of ovarian carcinoma patients with a pelvic mass. Gynecol Oncol. 2008;108:402-408.

6. Havrilesky LJ, Whitehead CM, Rubatt JM, et al. Evaluation of biomarker panels for early stage ovarian cancer detection and monitoring for disease recurrence. Gynecol Oncol. 2008;110:374-382.

7. Dong L, Chang XH, Ye X, et al. The values of serum human epidermis secretory protein 4 and CA125 assay in the diagnosis of ovarian malignancy. Zhonghua Fu Chan Ke Za Zhi. 2008;43:931-936. Chinese.

8. Montagnana M, Lippi G, Ruzzenente O, et al. The utility of serum human epididymis protein 4 (HE4) in patients with a pelvic mass. J Clin Lab Anal. 2009;23:331-335.

9. Huhtinen K, Suvitie P, Hiissa J, et al. Serum HE4 concentration differentiates malignant ovarian tumors from ovarian endometriotic cysts. Br J Cancer. 2009;100:1315-1319.

10. Abdel-Azeez HA, Labib HA, Sharaf SM, Refai AN. HE4 and mesothelin: novel biomarkers of ovarian carcinoma in patients with pelvic masses. Asian Pac J Cancer Prev. 2010;11:111-116.

11. Andersen MR, Goff BA, Lowe KA, et al. Use of a symptom index, CA125, and HE4 to predict ovarian cancer. Gynecol Oncol. 2010;116: 378-383. 
12. Chen GD, Li ZG, Qian DY, et al. The value of human epidermis secretory protein in the diagnosis of pelvic masses. J Pract Med. 2010;26: 2774-2776.

13. Ke L, Liu FH. The value of serum HE4 and CA125 in the diagnosis of ovarian cancer. Mod Med (Chic). 2010;10:85-86.

14. Liu GR, Wang AL, Liu Q, et al. Combined detection of serum CA125 and HE4 for ovarian cancer diagnosis and differential diagnosis. Chin $J$ Clin Lab Sci. 2010;28:119-121.

15. Ma L, Yan CL, Piao WH. The clinical application of serum human epidermis protein 4 in the aided diagnosis of ovarian cancer. Ningxia Med J. 2010;32:1038-1039.

16. Wang KY, Leng JH, Deng $\mathrm{H}$, et al. The value of combined detection of serum HE4 and CA125 in the diagnosis of ovarian cancer. Chin J Health Lab. 2010;20:1139-1140.

17. $\mathrm{Xu}$ CL, Yang YH, Wang HL. The value of serum human epidermis protein 4 epithelial in the diagnosis of ovarian cancer. Chin J Gynecol Obstet. 2010;26:684-686.

18. Yao YL, Liu Q, Li XY. The application value of joint inspections of serum HE4, TPS and CA125 in the diagnosis of ovarian cancer. Radiat J Immunol. 2010;23:409-411.

19. Lu MD, Chen DZ, Zhao J, et al. The expression of joint detection of HE4 and CA125 in ovarian tumors and its clinical significance. Chin Matern Child Health. 2010;5:3623-3625.

20. Liu YN, Ye X, Cheng HY, et al. Measurement of serum human epidermis secretory protein 4 combined with the CA125 assay in the differential diagnosis of endometriosis cyst and ovarian benign and malignant tumors. Chin J Obstet Gynecol. 2010;45:363-366.

21. Montagnana M, Danese E, Ruzzenente O, et al. The ROMA (risk of ovarian malignancy algorithm) for estimating the risk of epithelial ovarian cancer in women presenting with pelvic mass: is it really useful? Clin Chem Lab Med. 2011;49:521-525.

22. Allard J, Somers E, Theil R, Moore RG. Use of a novel biomarker HE4 for monitoring patients with epithelial ovarian cancer. J Clin Oncol. 2008;26:5535

23. Van Gorp T, Cadron I, Despierre E, et al. HE4 and CA125 as a diagnostic test in ovarian cancer: prospective validation of the risk of ovarian malignancy algorithm. Br J Cancer. 2011;104:863-870.

24. Moore RG, Miller MC, Disilvestro P, et al. Evaluation of the diagnostic accuracy of the risk of ovarian malignancy algorithm in women with a pelvic mass. Obstet Gynecol. 2011;118:280-288.

25. Kim YM, Whang DH, Park J, et al. Evaluation of the accuracy of serum human epididymis protein 4 in combination with CA125 for detecting ovarian cancer: a prospective case-control study in a Korean population. Clin Chem Lab Med. 2011;49:527-534.

26. Jacob F, Meier M, Caduff R, et al. No benefit from combining HE4 and CA125 as ovarian tumor markers in a clinical setting. Gynecol Oncol. 2011;121:487-491.
27. Holcomb K, Vucetic Z, Miller MC, Knapp RC. Human epididymis protein 4 offers superior specificity in the differentiation of benign and malignant adnexal masses in premenopausal women. Am J Obstet Gynecol. 2011;205:358. e1-e6.

28. Escudero JM, Auge JM, Filella X, Torne A, Pahisa J, Molina R. Comparison of serum human epididymis protein 4 with cancer antigen 125 as a tumor marker in patients with malignant and nonmalignant diseases. Clin Chem. 2011;57:1534-1544.

29. Chang X, Ye X, Dong L, et al. Human epididymis protein 4 (HE4) as a serum tumor biomarker in patients with ovarian carcinoma. Int $J$ Gynecol Cancer. 2011;21:852-858.

30. Bandiera E, Romani C, Specchia C, et al. Serum human epididymis protein 4 and risk for ovarian malignancy algorithm as new diagnostic and prognostic tools for epithelial ovarian cancer management. Cancer Epidemiol Biomarkers Prev. 2011;20:2496-2506.

31. Zheng H, Gao Y. Serum HE4 as a useful biomarker in discriminating ovarian cancer from benign pelvic disease. Int $J$ Gynecol Cancer. 2012;22:1000-1005.

32. Karlsen MA, Sandhu N, Høgdall C, et al. Evaluation of HE4, CA125, risk of ovarian malignancy algorithm (ROMA) and risk of malignancy index (RMI) as diagnostic tools of epithelial ovarian cancer in patients with a pelvic mass. Gynecol Oncol. 2012;127:379-383.

33. Kadija S, Stefanovic A, Jeremic K, et al. The utility of human epididymal protein 4 , cancer antigen 125 , and risk for malignancy algorithm in ovarian cancer and endometriosis. Int J Gynecol Cancer. 2012;22:238-244

34. Hamed EO, Ahmed H, Sedeek OB, Mohammed AM, Abd-Alla AA, Abdel Ghaffar HM. Significance of HE4 estimation in comparison with CA125 in diagnosis of ovarian cancer and assessment of treatment response. Diagn Pathol. 2013;8:11.

35. Azzam AZ, Hashad DI, Kamel NA. Evaluation of HE4 as an extrabiomarker to CA125 to improve detection of ovarian carcinoma: is it time for a step forward? Arch Gynecol Obstet. Epub January 30, 2013.

36. Yu S, Yang HJ, Xie SQ, Bao YX. Diagnostic value of HE4 for ovarian cancer: a meta-analysis. Clin Chem Lab Med. 2012;50:1439-1446.

37. Li F, Tie R, Chang K, et al. Does risk for ovarian malignancy algorithm excel human epididymis protein 4 and ca125 in predicting epithelial ovarian cancer: a meta-analysis. BMC Cancer. 2012;12:258.

38. Wu L, Dai ZY, Qian YH, Shi Y, Liu FJ, Yang C. Diagnostic value of serum human epididymis protein 4 (HE4) in ovarian carcinoma: a systematic review and meta-analysis. Int J Gynecol Cancer. 2012;22: 1106-1112.

39. Sandri MT, Bottari F, Franchi D, et al. Comparison of HE4, CA125 and ROMA algorithm in women with a pelvic mass: correlation with pathological outcome. Gynecol Oncol. 2013;128:233-238.
OncoTargets and Therapy

\section{Publish your work in this journal}

OncoTargets and Therapy is an international, peer-reviewed, open access journal focusing on the pathological basis of all cancers, potential targets for therapy and treatment protocols employed to improve the management of cancer patients. The journal also focuses on the impact of management programs and new therapeutic agents and protocols on

\section{Dovepress}

patient perspectives such as quality of life, adherence and satisfaction The manuscript management system is completely online and includes a very quick and fair peer-review system, which is all easy to use. Visit http://www.dovepress.com/testimonials.php to read real quotes from published authors. 